\title{
perifèria
}

Número 15, diciembre 2011

www.periferia.name

\section{Un paso hacia la responsabilidad}

Eva Bretones - Universitat Oberta de Catalunya ${ }^{1}$

\section{Domingo Barbolla, Esther Masa y Guadalupe Díaz (2011). Violencia Invertida. Cuando los hijos pegan a sus padres. Barcelona: Gedisa.}

La violencia no es un fenómeno nuevo. Lo nuevo es poder "escuchar" la voz y poner rostro a algunos hijos e hijas que ejercen violencia sobre sus progenitores. Lo nuevo ahora es su denuncia pública y la intervención de la judicatura en el conflicto familiar. ¿Por qué los hijos y/o hijas pegan a sus padres y madres? Una pregunta, cuánto menos inquietante, la que plantean y escenifican los autores, que transporta al lector "al abismo de la certeza" al replantearse éste su responsabilidad cómo ciudadano, ¿con pleno derecho?

Poner nombre a la sorpresa es la gran propuesta de Violencia Invertida ${ }^{2}$. Un estudio que, al hilo de la voz de sus protagonistas, da una explicación, siempre necesaria,

1 Eva Bretones es Educadora Social, licenciada en Filosofia y Ciencias de la Educación, magister en Investigación Básica y Aplicada en Antropologia y Dra. en Pedagogia per la UAB. Su trayectoria profesional ha combinado el acompañamiento educativo a adolescentes y jóvenes con dificultades de participación socio comunitaria y la docencia en la universidad. Profesora en el departamento de Pedagogia Aplicada de la UAB hasta el 2009, actualmente es profesora en el Grado de Educación Social de la UOC. Forma parte del grupo de investigación Mossa y Grafo de la UAB, y del grupo LES, de la UOC.

\footnotetext{
${ }^{2}$ En la exposición todas las frases extraídas literalmente del libro aparecen en cursiva.
} 


\section{perifèria}

Número 15, diciembre 2011

www.periferia.name

al complejo fenómeno de la norma contravenida en la gestión de la violencia aceptada: el hijo y/o la hija que ejerce la violencia contra sus progenitores.

Ejercer de modo inverso la violencia rompe con su conceptualización tradicional, dicen los autores. Aquello que intuimos nos es devuelto en el ejemplo, esto es, el reconocimiento de la existencia de una violencia legitimada por nuestra sociedad y nuestra cultura, desde la autoridad que da la edad y la posición para moldear ciudadanos pacíficos.

La violencia, subrayan, como respuesta biológica-cultural a la intromisión de las necesidades del sujeto, es un hecho universal que debe ser entendido desde el orden de la moral imperante como atributo para vivir. En este sentido, toda sociedad acuerda y pacta quién puede o no ejercer la violencia hacia los demás, y la de los hijos hacia los padres, nos dicen los autores, no está contemplada en ninguna cultura conocida desde la autoría legitimada.

Estamos frente al primer estudio realizado sobre este incómodo fenómeno, que da voz a los actores del conflicto y denuncia las fisuras de un sistema ausente y sorprendido ante la transgresión de la norma legitimada, lejos del morbo mediático. Una denuncia que nace de una lógica, la de dar respuesta a la percepción e interrogación de algunos profesionales. Este libro intenta responder a una demanda explícita formulada por profesionales de la Dirección General de Infancia y Familias de la Junta de Extremadura: ¿Por qué los hijos/as pegan a sus padres en entornos familiares objeto de tutela por la Administración Autonómica? ¿Cómo articular acciones tendentes a eliminar este tipo de acciones no deseables?

El reto al que se enfrentan los autores es inconmensurable. Más allá de las estadísticas y de la ausencia de matices, buscan respuestas a éstos y otros interrogantes a través de relatos personales y familiares que ponen cara a un problema que nace del funcionamiento "fallido" de una sociedad, la nuestra.

Una parte de los relatos ofrecidos es la de aquellos y aquellas que ya están "recluidos". En enero de 2010 son doce adolescentes los que comparten espacio 


\section{perifèria}

Número 15, diciembre 2011

www.periferia.name

vital en un piso tutelado. Desde la distancia espacial, temporal y emocional que supone el "aislamiento", relatan su experiencia, dando forma y significado a lo sucedido, a lo que están viviendo y a lo que esperan del futuro. Anabel, Aarón, Aníbal, Alejo, Alicia, Amanda, Andrés, Antonio, Alfonso y Adolfo son los jóvenes que en estas historias ejercen violencia sobre otros. De éstos, cuatro forman parte de la casuística concreta del hijo/hija que violenta a su padre/madre.

En todos los casos el cumplimiento de las medidas impuestas por orden judicial ha supuesto alejarse de su círculo de relación para dar paso a un lapsus temporal y espacial en el que, "desarmados" de todo lo que antes les otorgaba significado e identificación, deben reorganizarse.

No existe un modelo estándar en sus historias, aunque algunas evidencias son punto de encuentro en todas ellas. En palabras de los autores la equidad de género sería la primera ( 6 chicas y 6 chicos) y la pertenencia de clase, la segunda. Característica compartida la del fracaso escolar, con diferencias en la extensión de la actitud violenta del hogar a las aulas. Todos manifiestan la voluntad de aprovechar la formación que desde el centro se les brinda. Una voluntad que se desmonta frente a las limitadas expectativas formativas que verbalizan, que poco conectan con sus pretensiones económicas. En todos ellos, abrumadora mayoría de padres ausentes.

Asumido el problema y fuera del espacio físico y humano en el que no supieron, pudieron o quisieron resolverlo, ¿qué significará volver a casa? Diferentes opiniones en función del tiempo "vivido" en el centro. Para quien acaba de llegar, y con sensación de abandono, nada acabará con el problema. Para los jóvenes que los reciben, el tiempo sumado permite una reorientación en la mirada. Las normas para todos implican acuerdo, compromiso y confianza. El $70 \%$ de los chicos y chicas que "traspasan" estos centros reinciden en sus conductas violentas.

¿Qué hacen los progenitores para contribuir a la resolución de un conflicto compartido? He aquí la lógica novedosa, la propuesta por los autores, a la 


\section{perifèria}

Número 15, diciembre 2011

www.periferia.name

comprensión e interpretación de las dinámicas familiares invertidas.

Revisados todos los antecedentes estadísticos y teóricos sobre el fenómeno, los autores consideran que la teoría propuesta por el pediatra Aldo Nouari ${ }^{3}$ es el marco en el que entender la respuesta infantil "contravenida". Una propuesta provocadora que encuentra en la voz de los implicados su escenificación.

Tres piezas conforman el puzzle propuesto por Nouari: el papel de la madre, el papel del padre y el tabú del incesto. Aldo Nouari presenta a la madre como eterna cuidadora de lo sagrado, la vida. La madre es presente, es la consciencia retardadora de la muerte. La segunda pieza es el padre. La figura paterna cubre otro papel, el de la lógica del tiempo: la muerte, el precio de la consciencia. Según Nouari dos impulsos aterrorizan al hombre: la angustia segura de la muerte y el instinto básico de la sexualidad (continua y desbordante). Vida a dar y muerte a finalizar forjan la biología masculina. Los hijos y las hijas han de ser educados en esta dualidad, realista dice Nouri. Es desde estos dos espejos proyectados como antagónicos desde donde tiene vigencia la realidad. Dos caras de una misma moneda que tendrán un continuo diálogo en la formación del niño y la niña y en su respuesta hacia los progenitores y en definitiva hacia el entorno, dice él normalizado, para convivir con otros en su espacio social y cultural.

La tercera y última pieza en esta historia es el reparto de mujeres en la sociedad del origen, vinculada ésta de nuevo a las dos tensiones enfrentadas en el hombre. Instaurado el tabú del incesto, se acaba con la lógica egoísta del macho más fuerte que fecundaba a demanda de sus impulsos. La derrota del más fuerte instaura una norma sagrada, el reparto equitativo de las hembras no vinculadas consanguíneamente. Ley sagrada que une procreación y muerte, leyes básicas que se trasladan a las generaciones futuras.

\footnotetext{
3 en Padres permisivos, hijos tiranos. (2005). Barcelona: Ediciones B.
} 


\section{perifèria}

Número 15, diciembre 2011

www.periferia.name

A partir de estas tres piezas, clave en la propuesta interpretativa realizada, los autores afirman que la manifestación violenta y violentada de hijos e hijas hacia sus padres y madres es fruto de la ausencia del rol de padre en las relaciones familiares. Sin el rol de padre interiorizado, la toma de consciencia que opera en el niño o la niña se perfila en contra al generar continuas exigencias a los progenitores sin haber experimentado el duelo por el tránsito hacia la muerte en la cotidianeidad del no.

En los proyectos familiares sin padre, la madre sintetiza ambos roles, decantándose por uno. Un proceso que los hijos viven con angustia. En aquellos casos donde la angustia no encuentra espacios de canalización se torna violencia hacia el progenitor, generalmente, más débil y habitualmente único, que es la madre. Lo atestiguan Almudena, Araceli, Ángela, Adela, Amparo y Aurora, las madres que en estas historias singulares ponen rostro a los agredidos. Las progenitoras son, como corroboran los relatos, las que en la mayoría de los expedientes sobre violencia invertida aparecen como víctimas propiciatorias de la agresión. Y los padres los grandes ausentes.

El desencuentro es, dicen los autores, la inseguridad del niño y/o la niña, que al no saber cómo gestionarla por no haber experimentado el no, responde con violencia hacia quienes entiende que son los responsables de la misma.

La evidencia es aplastante, el hijo y/o la hija violenta se construye. Y lo hace sobre todo en sus primeros años de socialización en el medio y con los otros, principalmente con sus referentes parentales. Las historias relatadas perfilan relaciones singulares y por muchos conocidas: ausencia o poca presencia de normas y límites, híper protección, etc. Y es, en todos los casos, en la adolescencia cuando el desencanto se transforma en agresión física.

En los relatos se visibiliza, lo que los autores denominan ausencia de empatía. Algo que se aprende hacia los dos años en el entorno más cercano y que va completándose a medida que se extienden las redes de socialización. La empatía se 


\section{perifèria}

Número 15, diciembre 2011

www.periferia.name

adquiere a través de las conductas observadas, transmitidas y ejercidas. Siendo un hábito para quienes las han interiorizado, pero de difícil desarrollo, cómo ponen de manifiesto los profesionales, en adolescentes que nunca la han puesto en práctica.

El papel del padre y la madre, confirman, es un ítem fundamental en la comprensión de la violencia invertida en el plano de la interacción familiar. Pero, ¿qué lleva a una madre a denunciar a su hijo y/o hija? En el presente cultural de nuestras sociedades complejas, nos recuerdan los autores, hemos generado particulares formas de reordenar el bien y el mal construyendo instituciones a tal función. Hemos judicalizado la autoridad. Hemos convertido al Estado en el último garante a la hora de delimitar y sancionar la violencia, venga ésta de donde venga. Lejos de buscar culpables, el juego al que nos abocan los autores implica, una vez más, asumir la globalidad en nuestro interés por los porqué. Una propuesta atrevida que nos implica a todos y a todas.

Desde mi experiencia con adolescentes con dificultades de participación familiar, como formadora de educadoras y educadores sociales, como mujer, madre y ciudadana, la lectura de esta obra se me revela todo un atrevimiento. Poner nombre a lo que nos sucede e interpretarlo a la luz del relato de quien es partícipe nos permite un cierto alejamiento de la neurosis en la que acabamos viviendo. Es la gran propuesta de esta obra.

Y no hay atrevimiento sin polémica. Los interrogantes se multiplican y las posibilidades del estudio se diversifican. ¿Cómo alimentar junto a otras disciplinas el modelo teórico propuesto? Parece inevitable tener que seguir acompañando a los protagonistas de ésta y otras historias a fin de no generar sospechas sobre tipologías familiares, edades y clases sociales. ¿Qué ha sucedido con éstos 12 chicos y chicas? El estudio longitudinal se reclama pertinente, aunque no sólo. ¿Qué sucede con el $30 \%$ de chicos y chicas que también "pasaron por centros de menores" y no reiteran sus conductas violentas? ¿Qué sucede con aquellas familias que en similares situaciones resuelven sin violencia? La oportunidad, y con ella la viabilidad en los cambios personales, familiares y sociales también busca su espacio 


\section{perifèria}

Número 15, diciembre 2011

www.periferia.name

en la investigación. Pero hay más, ¿cómo incorporar al análisis de la violencia "aceptada" a las instituciones y a sus profesionales? Llámense éstos educadores (centro de menores) y/o políticos (Estado).

La mochila de cada lector incorporará a mi lista de interrogantes (y posibilidades) los propios, porque a todos nos apremia saber qué podemos hacer como sujetos partícipes de este entramado que hemos acordado en denominar "violencia". Gracias por hacernos partícipes de nuestra responsabilidad.

\section{Bibliografía}

Bourdieu, P. (2000). La dominación masculina. Barcelona: Anagrama.

Bretones, E. (Coord.) (2011) Família i Educació Social. Barcelona: EdiUOC

Cyrulnick, B. (2002). Los patitos feos: la resiliencia: una infancia infeliz no determina la vida. Barcelona: Gedisa.

Roudinesco, E. (2004). La familia en desorden. Barcelona: Anagrama. 